\title{
The Psychologisation Conversation: An Introduction
}

As part of this issue of Human Resource Management Journal, we present a collection of four articles that represent a conversation about the 'psychologisation' of the human resource management (HRM) and employment relations (ER) fields of study. The first article is a provocation arguing 'The case for psychology in human resource management research' coauthored by Ashlea Troth and David Guest. This is followed by the first of two commentaries in response to this provocation, 'The psychologisation of employment relations, alternative models of the employment relationship, and the OB turn' authored by John Budd. The second is authored by Bruce Kaufman and pronounces 'The real problem: The deadly combination of psycholgising, scientism, and normative promotionalism take strategic HRM down a thirty-year dead end'. The final article in this conversation is a short response by John Godard, 'Psychologisation revisited', responding to Troth and Guest as well as building from his original article 'The psychologisation of employment relations?' published in HRMJ in 2014 (Volume 24, Issue 1).

This quadriptych presents a lively debate that is occurring in our discipline today. Our aim in this introduction is not to discuss all aspects of this debate (that is done with great passion and adeptness in the articles that follow), but instead to outline the essence of why this debate is taking place. At the heart of the conversation is the question of whether HRM and ER scholarship is being dominated by a micro-level, largely positivist industrial/organizational (I/O) or work psychology approach to research questions, to the detriment of a broader perspective that addresses the multiple levels of analysis that are required to understand the complexity of the employment relationship and the management of people at work. 
The industrial relations field of study was built on pluralist labour relations roots, whereas the HRM tradition focuses on a more unitarist perspective of manager-employee relations in the workplace. Fundamentally, the two fields represent different assumptions about the employment relationship. I/O psychology presents yet another focus, which is embedded at the micro or individual level of employees and pays less attention to the employment relationship per se, instead focusing on how people experience work. It is not surprising, therefore, that debate between scholars working across these fields has always been lively: studying employees or workers from different perspectives, each starting from very different mindsets and assumptions.

One of the critiques targeted at the I/O psychology field by some HRM and ER scholars is the focus on a 'pure science' approach to analysing employees. This produces rigorous research that meets many of the criteria for publication in the top journals in the management field, hence the argument that such research has come to dominate our publication strategies. The counter to this benefit is that the relevant research questions in HRM and ER fields are much broader. The EURAM E-News Quarterly (April 2019) highlighted this concern as part of its Presidential Activities that convene presidents of other academic management societies to discuss the state of management research. They conclude that:

"The currently dominant reductionist scientific approach that $[\ldots]$ promotes quantitative method sophistication for a more correct identification (estimation) of causal effects - which is necessary - to the detriment of building on existing literature and theories has given rise to a scholarship crisis and doesn't address managerial/organizational complexity in a holistic way as managers and other employees experience it" (Durand \& Castañer, 2019). 
This theme is picked up and debated in the articles published here.

The four articles present an insight into the intense debate that emerges when the HRM, ER and I/O Psychology fields of study collide. Troth and Guest argue the case for how adopting a psychological perspective has enriched the HRM field, rebutting prior critiques and identifying core contributions that have been made. Budd responds, also speaking further to Godard's 2014 article, and highlighting how "attention is being pulled away from conceptualizing the nature of the employment relationship". He presents a comprehensive overview of the frames of reference relevant to the employment relationship. Kaufman's response focuses specifically on the HRM and performance literature in order to "put the macro-level part of the psychology-HRM debate back on the table". He highlights the analytical flaws that he perceives are present in extant research in both HRM and I/O Psychology research, suggesting ways forward for the strategic HRM literature.

We will refrain from further comment here but hope that the articles that follow stimulate a productive debate that helps to clarify the boundaries and complementarities of our respective fields and how we can benefit scholarship by increasing our appreciation of the multidisciplinary and multi-level nature of work and employment and, consequently, our fields of study. Human Resource Management Journal continues to welcome submissions from HRM, ER, and I/O Psychology scholars, as well as many others, provided the research speaks to the management of people at work.

\section{References}

Durand, T., \& Castañer, X. (2019). Letter from President, Thomas Durand, and VP External Relations, Xavier Castañer. EURAM E-News, Quarterly, April: 
http://euramonline.org/newsroom/newsletter/83-newsroom/newsletters/672-spring-news-

2019.html (accessed 6 December 2019). 